\title{
Nephrology in the global environment
}

\author{
John W. M. Agar ${ }^{1} \cdot$ Katherine A. Barraclough $^{2}$. Giorgina B. Piccoli ${ }^{3,4}$
}

Received: 30 January 2019 / Accepted: 2 February 2019 / Published online: 22 February 2019

(c) Italian Society of Nephrology 2019

'How long is a piece of string?' is a common expression used to indicate that there is no definite answer ... that the boundaries of experience are ever-expanding, with no certain end in sight. It is an expression that could be aptly applied to concepts in healthcare.

In the twentieth century, healthcare focused on the diagnosis and treatment of human disease ... on the human condition. But, in the twenty-first century, healthcare horizons are rapidly expanding to embrace a wider ecological and environmental ethic_chivvied along by the gathering clouds of climate change.

We who work in healthcare can no longer sit back and think 'fellow man' without considering the wider perspective of our planet, and its' myriad eco-systems and interdependent life-cycles. Healthcare must globalize into planetary health - of and in which human health is but one cog.

Nephrology, above and beyond all other specialties, is the study, understanding, and management of homeostasis. Homeostasis, as defined by the Encyclopedia Britannica is:

“... any self-regulating process by which biological systems tend to maintain stability while adjusting to conditions that are optimal for survival. If homeostasis is successful, life continues; if unsuccessful, disaster or death ensues. [Stable homeostasis is] a dynamic

This article is part of the topical collection on Home Haemodialysis.

John W. M. Agar

johna@barwonhealth.org.au

1 Renal Services, University Hospital Geelong, Barwon Health and Deakin University School of Medicine, 74-76 Swanston Street, Geelong, VIC 3220, Australia

2 Department of Nephrology, Royal Melbourne Hospital, Parkville, Australia

3 Service de Nephrologie, Centre Hospitalier Le Mans, Le Mans, France

4 Department of Clincal and Biological Sciences, University of Torino, Torino, Italy equilibrium in which continuous change occurs, yet relatively uniform conditions prevail."

As the keepers of human homeostasis, nephrologists have a duty of care to the homeostatic equilibrium of the wider environment in which we live. Yet, to date, we have played that hand poorly.

Litre by litre, kilowatt by kilowatt, kilogram by kilogram, nephrology — and the dialysis modalities nephrologists' oversee-accounts for more individual water and power consumption, and creates greater person by person infectious waste than any other sector in healthcare. So much for our homeostatic husbandry!

This author has previously documented the underwhelming performance of nephrology, to date, in exploring new ways to re-use and/or re-direct reverse osmosis waste water, in harnessing renewable power sources to drive our dialysis systems, and in innovating new ways to better manage and/or re-purpose dialysis waste [1-4]. But, to date, global dialysis practice has shown little sign of substantive change.

No national scientific meetings yet list sub-heading choices like 'environment', 'sustainability', or 'resource management', among their abstract topic options. Mainstream national and international meetings have not, in the main, offered time or space for environmental symposia.

However, hope does line the horizon. The Australian and New Zealand Society of Nephrology (ANZSN) is now offering research encouragement in the environmental space [5] and is the first known national body yet to do so. The International Society of Nephrology (ISN) has invited an internationally renowned environmentalist to deliver a nonmedical Plenary at the 2019 World Congress in Nephrology [6]. The European Renal Association-European Dialysis and Transplant Association (ERA-EDTA) has recently committed to a broad range of initiatives aimed at 'greening' the renal sector in EU countries [7]. A pending editorial in the Brazilian Journal of Nephrology will seek to alert the Brazilian nephrology community to matters environmentalespecially in the dialysis field. Nephrology [8] and Kidney 
Fig. 1 Jean Yves Blais. Home. Romania 2018. Jean Yves Blais is free lance French photographer interested in hidden beauty and forgotten people. This image derives from a series of photos recently taken in the Rom villages in Romania. The village here depicted is built on a dump; it reminds us of the complex relationship between humans and waste, and how large scavenger communities may strive around waste dumps, as in the better known cases of the Smokey Mountain in Manila or of the "garbage slums" growing outside of many large African cities

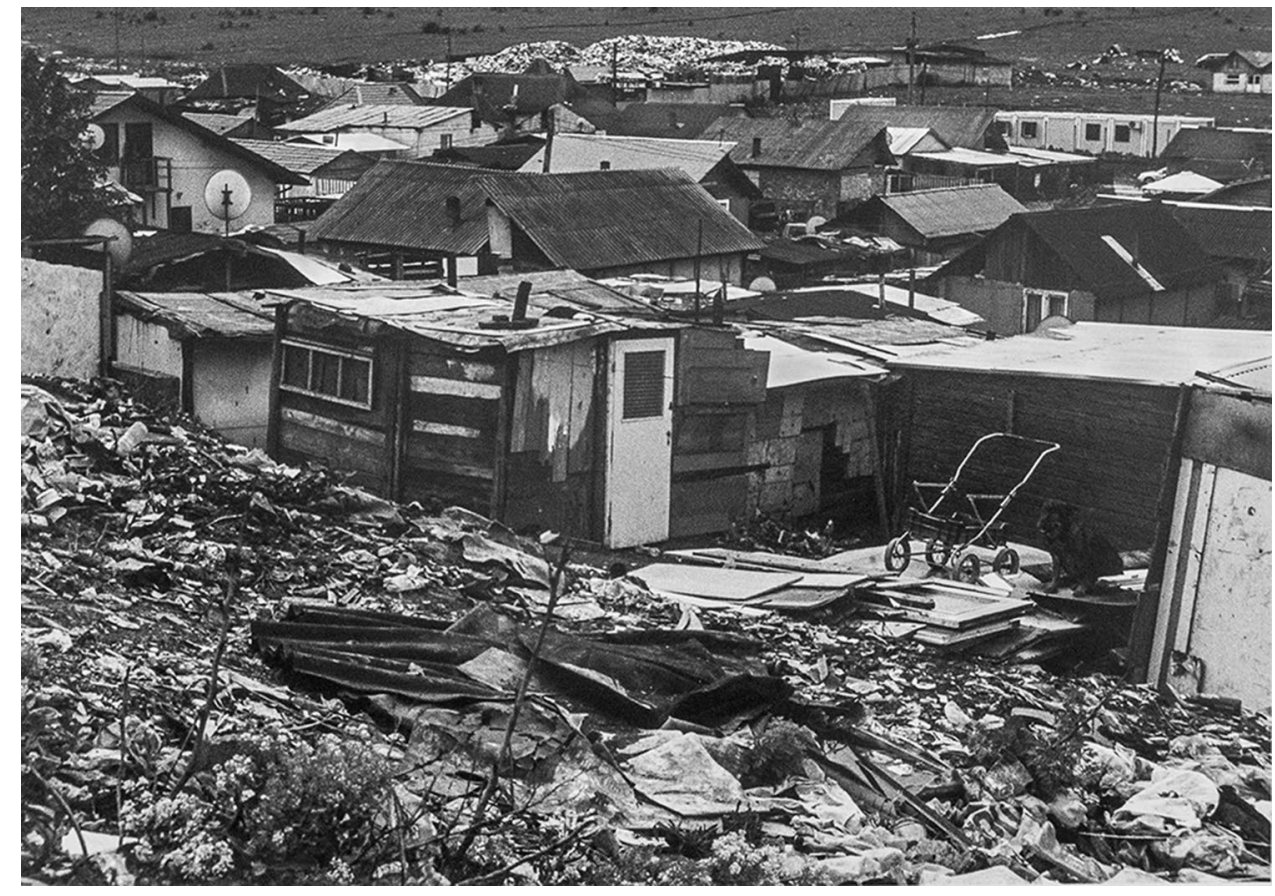

International [9] have both recently published papers in the environmental space.

On a more generic basis, the Lancet has recently established a new journal-Lancet Planetary Health [10]designed to lift the global focus of healthcare from its traditionally narrow view to a wider environmental and ecological level.

Despite these early but significant steps in the right direction, the wider nephrology and dialysis communities appear to remain largely unaware. But, as dialysis patient numbers burgeon across the developed and developing world, and as resource-hungry dialysis processes proliferate, the need to quantify, to document, and to alter toward more resource and waste-wise practices becomes ever more urgent.

This editorial seeks to sound yet another call to a greater environmental awareness across our specialty. Let us hope it is an awareness call that is heeded (Fig. 1).

\section{Compliance with ethical standards}

Conflict of interest The authors declare that they have no conflict of interest.

Ethical approval This article does not contain any studies with human participants performed by any of the authors.

\section{References}

1. Agar JWM (2008) Recycling dialysis wastewater: 'the elephant in the room'. Am J Kid Dis 52(1):10-12

2. Agar JWM (2012) Personal viewpoint: hemodialysis-water, power and waste disposal. Re-thinking our environmental responsibilities. Hemodial Int 16(1):6-10

3. Agar JWM (2013) It is time for green dialysis. (Editorial). Hemodial 17(4):474-478

4. Agar JWM (2015) Green dialysis: The Environmental Challenges Ahead. Seminars in Dialysis (Special Edition: "Views, Visions and Vistas in Dialysis"). March-April 28(2), pp 186-192

5. Australian and New Zealand Society of Nephrology-ANZSN Awards (2019): See: https://www.nephrology.edu.au/awardsfell owshipsandgrants/anzsnawards.asp. Accessed 30 Jan 2019

6. Flannery T (2019) Keeping the climate safe. See: https://cm.theis n.org/cmPortal/searchable/WCN2019/config/normal\#!sessiondet ails/0000009350_0. Accessed 30 Jan 2019

7. Blankestijn PJ et al (2018) ERA-EDTA invests in transformation to greener health care. Nephrol Dial Transpl 33(6):901-903

8. Barraclough KA, Holt SG, Agar JWM (2015) Climate change and us: what nephrologists should know. Nephrology (Carlton) 20(10):760-764

9. Barraclough KA, Blashki GA, Holt SG, Agar JWM (2017) Climate change and kidney disease-threats and opportunities. Kidney Int 92(3):526-530

10. Welcome to the Lancet Planetary Health (2019) Inaugural Edition of Lancet Planetary Health: Editorial. https://www.thelancet. com/journals/lanplh/article/PIIS2542-5196(17)30013-X/fulltext. Accessed 30 Jan 2019

Publisher's Note Springer Nature remains neutral with regard to jurisdictional claims in published maps and institutional affiliations. 